\title{
Twice a day neuromuscular electrical stimulation post- immobilization alters the mechanical properties and the histomorphometry of the skeletal muscle
}

\author{
Leonardo Carvalho ${ }^{1 *}$, Juliana Polizello², Fernando Freitas ${ }^{3}$, Natália Padula ${ }^{3}$, Antonio Shimano ${ }^{2}$ and Ana Claudia Mattiello-Sverzut ${ }^{2}$
}

*Correspondence: leounifal@gmail.com

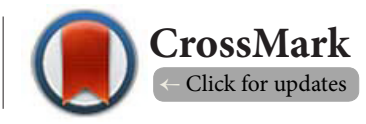

'Division of Physiotherapy, Federal University of Alfenas, Alfenas, Brazil.

${ }^{2}$ Department of Biomechanics, Medicine and Rehabilitation of the Locomotor Apparatus, University of São Paulo, Brazil.

${ }^{3}$ Ribeirão Preto of School Medicine, University of São Paulo, Brazil.

\begin{abstract}
Background: The responses to the use of neuromuscular electrical stimulation (NMES) technique, once or twice a day, are not well described in literature. In this direction, we measured the biomechanical properties and morphological responses of NMES, applied once or twice a day to the gastrocnemius muscle of female rats after cast immobilization in comparison with both sham control and immobilized control groups.

Methods: Eighty Female Wistar rats (Body mass \pm SDg; $210 \pm 10 g$ ) were divided into five groups: Control (CG); Immobilized (IG); Immobilized then freed (IFG); Immobilized and subjected to NMES once a day (1ESIG) and another twice a day (2ESIG). All groups that suffered cast immobilization were kept in a shortened position for fourteen days, and then NMES was applied once or twice a day for ten consecutive days. The assessments included the mechanical properties of load and elongation at the limit of proportionality, as well as the resilience obtained from the load versus elongation graph. The crosssectional area (CSA), the different fiber type proportions and the perimisial connective area were measured.

Results: There was restoration of load at the limit of proportionality (LLP), but not resilience, in the 1 ESIG and 2 ESIG, as well as restoration of atrophy (CSA) of type I (TIF), type IIad (TIIadF) and type IId (TIIdF) fibers in the $1 \mathrm{ESIG}$, but not in the $2 \mathrm{ESIG}$. An induction of the TIIcF proportions in the $1 \mathrm{ESIG}$ and $2 \mathrm{ESIG}$, and a reduction of the TIIad in the 1 ESIG were verified.

Conclusions: The muscle remobilization intensity can, influence the recovery responses postimmobilization either positively or negatively, for it was observed that NMES once a day can recover most mechanical (except resilience) and structural parameters of gastrocnemius muscle after casting, whereas twice daily, promoted deleterious effects to the much clearer muscles. Moreover, the animals free movement allowed them to identify their own mobilization limits, which did not cause neither mechanical nor structural overload in the evaluated muscles.
\end{abstract}

Keywords: Immobilization, gastrocnemius muscle, electric stimulation, skeletal muscle

\section{Introduction}

Immobilization is known to promote deleterious changes in the skeletal muscle, such as cellular atrophy [1], reduction of extensibility, decrease in the amount of mitochondria, capillary density, and the ability to generate force as well as the increase in intramuscular connective tissues, among others [2]. The mechanical stress provoked by spontaneous or induced muscle contraction regulates cellular activity by the mechanism of cell transduction, influencing the morphofunctional aspects $[3,4]$ through a complex signaling cascade that involves membrane proteins, intermediate muscle filaments, and contractile proteins [5]. The cross-sectional fiber area and the myosin heavy chain (MHC) are components known to be influenced by variations in muscle tension. It has been reported that, short- 
Carvalho et al. Musculoskeletal Biology 2015,

term training induces collagen expression possibly linked to a greater force production during concentric, eccentric and isometric contractions in association with these changes [6]. Consequently, these alterations modify the mechanical properties of the bone-tendon-muscle-tendon-bone complex $[7,8]$, reinforcing or weakening the mechanical responses to contraction stress.

Techniques such as neuromuscular electrical stimulation (NMES) have been used before and after a given period of immobilization in an attempt to restore the ability of the muscles to support the tissues and to transmit external forces to them. The use of these techniques during immobilization triggers a considerable increase in glycogen reserves, maintains cellular tropism, reduces the proliferation of connective tissue [9] preserves the cross-sectional area [10] and protein synthesis [11] and re-establishes some mechanical properties of the striated skeletal muscle [12]. NMES is commonly applied at a once a day frequency during clinical rehabilitation practice $[13,14]$, however currently, some studies show the possibility of using this resource for more than once a day in rehabilitation protocols [15-17]. Nevertheless, the specific tissue responses to this intensity of stimulation have not been described in the literature. Thus, the aim of the present study was to assess and compare the morphofunctional effects of NMES applied once or twice a day to the gastrocnemius muscle of female rats after 14 days of cast immobilization in a shortened position.

\section{Methods}

\section{Groups}

Eighty female Wistar rats (Body mass \pm SDg; $210 \pm 10$ g) were provided by the Central Animal Facilities of the University of São Paulo's (USP) Ribeirão Preto Campus. The animals were kept in pairs in plastic cages measuring $41 \times 34 \times 16 \mathrm{~cm}$ in a room with controlled temperature $\left(24^{\circ} \mathrm{C}\right)$ on a 12 hours light/12 hours dark cycle, with free access to water and food in the Animal Facilities of the Bioengineering Laboratory at the Medicine college of the USP in Ribeirão Preto. The project was approved by the Ethics Committee for the Use of Animals (CEUA), Ribeirão Preto Campus, USP (Protocol no 06.1.692.53.8) and followed the norms of the Guide for Care and Use of Laboratory Animals (National Research Council, 1996).

The animals were divided into groups of 16 rats each, with 10 animals being used for the mechanical assay and six for the histochemical analysis. The groups were set up as follow: the immobilized group (IG)-the right hind limb was immobilized for 14 consecutive days then the animals were euthanized; the immobilized and once a day electrostimulated group (1ESIG)-after immobilization for 14 days, the animals were subjected to NMES once a day for 10 days and then allowed to move freely in a cage; the immobilized and twice a day electro stimulated group (2ESIG)-similar to the previous group but electrostimulated twice a day; the immobilized and then free group (IFG)-the animals were immobilized for 14 days and then allowed to move freely in their cage for 10 days; the control group (CG)-the animals were housed in a plastic cage for 14 days in order to match the period of contention of the animals in the remaining groups.

For the immobilization and NMES procedures the animals were anesthetized with a combination of ketamine hydrochloride $(80 \mathrm{mg} / \mathrm{kg})$ and xylazine hydrochloride $(15 \mathrm{mg} / \mathrm{kg})$, at the dose of $0.05 \mathrm{ml}$ of the mixture per $100 \mathrm{~g}$ body mass through the intraperitoneal route. The application of this anesthetic mixture is often reported in different studies $[10,11]$. In this study, the present combination was adopted because of anesthesy time being a dependent of the dosage which minimized the effects induced by the animal's immobility in the referred period, knowing that the quantity of the applied anesthesic controlled and was enough only for the period of carrying out the procedures.

At the end of the experimental procedure the animals were weighed and sacrificed with an overdose of the combined anesthetics.

\section{Immobilization procedure}

The right hind limb of the animal was immobilized with a plaster cast applied to the pelvis, the hip (neutral position) and the fully extended knee, while the ankle joint was left in plantar flexion for 14 days. For details, see Mattiello-Sverzut et al. [10].

\section{Procedure of NMES}

A BIOSET (Bioset, São Paulo, Brazil) Physiotonus Four current generator with biphasic (depolarized) low frequency and pulses of short duration applied at controlled frequencies was used for NMES. The parameters used for stimulation were $50 \mathrm{~Hz}$ frequency, $8 \mathrm{~s} / 22 \mathrm{~s}$ on/off cycles, $250 \mu \mathrm{s}$ pulse width, and an intensity of approximately $1 \mathrm{~mA}$ (measured with a resistance of $100 \Omega$, in a pilot study), capable of promoting a sustained and visible muscle contraction. Before the NMES procedure, the animals were shaved in the lumbar region and in the middle of de calf of the gastrocnemius muscle of the right hind paw in order to facilitate electric current conduction. Two electrodes were used for NMES, the first in a rectangular shape (area: $15 \mathrm{~cm}^{2}$ ) was fixed in the animal's lumbar region. The second electrode that was used, made of carbon-silicon in the shape of a pen (area: $0.29 \mathrm{~cm}^{2}$ ), was put on the middle of the calf.

After the 14 consecutive days of immobilization, the NMES protocol was applied for 10 minutes once a day (in the morning) or twice (in the morning and in the afternoon with a six hour interval) to the different groups.

\section{Mechanical assay}

The right hind limb of the animals subjected to the mechanical assay was dissected by hip disarticulation. The gastrocnemius muscle was exposed, preserving its origin in the distal third of the femur and its insertion in the heel. A special accessory was used for fixing and testing of traction, which allowed 
the gastrocnemius muscle to undergo the trial preserving its muscular origin and insertion. For the trial a universal testing machine was used, brand EMIC ${ }^{\circledR}$-DL10000 model (EMIC, São José dos Pinhais, PR, Brazil) equipped with a load cell of $10 \mathrm{Kgf}$. The adapted parameters for the feat were a pre-load of $0.30 \mathrm{Kgf}$ where the rate of the test was $10 \mathrm{~mm} /$ $\mathrm{min}$ and the load as well as the elongation limits were 8 $\mathrm{Kgf}$ and $25 \mathrm{~mm}$ respectively [12]. For each increase of load applied to the muscle a value was obtained resulting from elongation, which enabled the construction of graphs for the analysis of the mechanical properties of resilience, load and elongation in the proportionality limit. This limit is the last point in the linear segment of the load versus elongation graph. The coordinates obtained at this point represent the proportional load and elongation. Resilience is defined as the capability that the material has in absorbing energy in the elastic fase. In this study it was obtained through finding the area of the triangle beneath the load versus elongation curve during this fase.

\section{Morphological and morphometric analysis}

Two portions of the central region of the middle of the calf of the gastrocnemius muscle (medial and lateral) were frozen in liquid nitrogen and stored in a freezer at $-80^{\circ} \mathrm{C}$. For histological processing the fragments were cut into $5-\mu \mathrm{m}$ thick cross-sections with a Leica CM 1850UV cryotome (Leica Microsystems Inc, Chicago, IL, EUA) at a temperature of $-25^{\circ} \mathrm{C}$. The sections were collected on $24 \times 50 \mathrm{~mm}$ coverslips, stained with hematoxylin-eosin (HE) and processed for the determination of myofibrillar adenosine triphosphatase (mATPases, E.C.2.1.3.5.7.9.1) at $\mathrm{pH} 4.3,4.6$ and 9.9, in the Laboratory of Neuropathology of the Department of Pathology, FMRP-USP, according to routine methods for skeletal muscle processing $[18,19]$. The slides were analyzed qualitatively under a Leica DM 2500 light microscope.

Morphological analysis of muscle tissue was performed with HE. Percentage of morphological alterations (nuclear centralization, lobulated fibers, hyaline necrosis, cells on degeneration and regeneration, splitting cells, central core and basophilic halo) was determined considering the total number of cells for each fragment from each muscle in the groups studied.

The images of the slides processed at $\mathrm{pH} 4.6$ were used for morphometric analysis. The images were captured with a Leica DM 2500 light microscope connected to a Leica DFC 300FX digital videocamera and to a microcomputer equipped with Qualiview-Atonus software (Atonus, São José dos Campos, SP, Brazil), which permitted cell count and measurement of the section area of the fibers. Three fields were evaluated in the deep region of each portion (lateral and medial) of the gastrocnemius muscle. The deep region of both portions was chosen for collection because it contains a higher concentration of different fiber types. According to Staron et al., [18], type I, Ic, Ilc, Ila, Ilad, Ild, IIdb and Ilb fibers are present in the deep region of the gastrocnemius muscle. The quantity of perimysial connective tissue in the fields evaluated was determined using Qualiview. The margins and the areas of the cross-sections of the fibers and vessels were measured and subtracted from the total area of the field evaluated $\left(91860.51 \mu \mathrm{m}^{2}\right)$, and the result corresponded to the quantity of perimysial connective tissue.

\section{Statistical analysis}

Data are reported as means $\pm S D$. The Kolmogorov-Smirnov test was first applied to the results to assess the normality of the sample and was followed by ANOVA and by the TukeyKramer test when the sample was found to be normal. When non-normal distribution was observed, the data were analyzed by the Kruskal-Wallis test followed by the Dunnet test. The level of significance was set at $5 \%$ in all analyses.

\section{Results \\ Mechanical properties}

The boxplot in Figure 1 indicates the results obtained from the analysis of the mechanical properties. Immobilization of the gastrocnemius muscle reduced the properties of Load at the Limit of Proportionality (LLP) (IG vs CG; $P<0.05)$ and resilience (IG vs CG; $P<0.05$ ) compared to $C G$, but the property of elongation at the limit of proportionality remained unchanged (IG vs CG; $P>0.05$ ).

Free mobilization was able to restore the Resilience and LLP properties compared to the immobilized muscle (IFG vs IG; $P<0.05)$. Free mobilization also showed better responses to the Resilience (IFG vs 1ESIG, 2ESIG; $P<0.05$ ) and Elongation at the Limit of Proportionality (ELP) (IFG vs 2 ESIG; $P<0.05$ ) compared to the electrostimulated muscles. NMES applied once a day to the gastrocnemius muscle favored the reestablishment of the LLP (1ESIG vs CG; $P>0.05 ; 1$ ESIG vs IG; $P<0.05$ ), whereas NMES applied twice a day presented values significantly lower to Resilience (2ESIG vs CG; IFG; $P<0.05$ ), and ELP (2ESIG vs CG; 1ESIG; IFG; $P<0.05)$.

\section{Morphology and morphometry}

Qualitative analysis of the gastrocnemius muscle (HE) revealed that immobilization induced important signs of tissue abnormalities as necrosis and cell degeneration, hyaline necrosis and nuclear centralization, being the lateral portion of the gastrocnemius muscle most affected. The remaining groups submitted to immobilization showed necrosis and cell degeneration signs in an expressive way in both regions evaluated, however, these same groups showed regeneration of muscle fibers in the lateral portion. The medial portion of the IFG showed histological changes similar to those observed in the IG group, demonstrating increased amounts of nuclear centralization and necrosis and cell degeneration. The percentage of muscle fibers with morphological changes in each group are shown in Table 1, however, it is noted that less than five percent of the cells of the muscles evaluated were affected. 


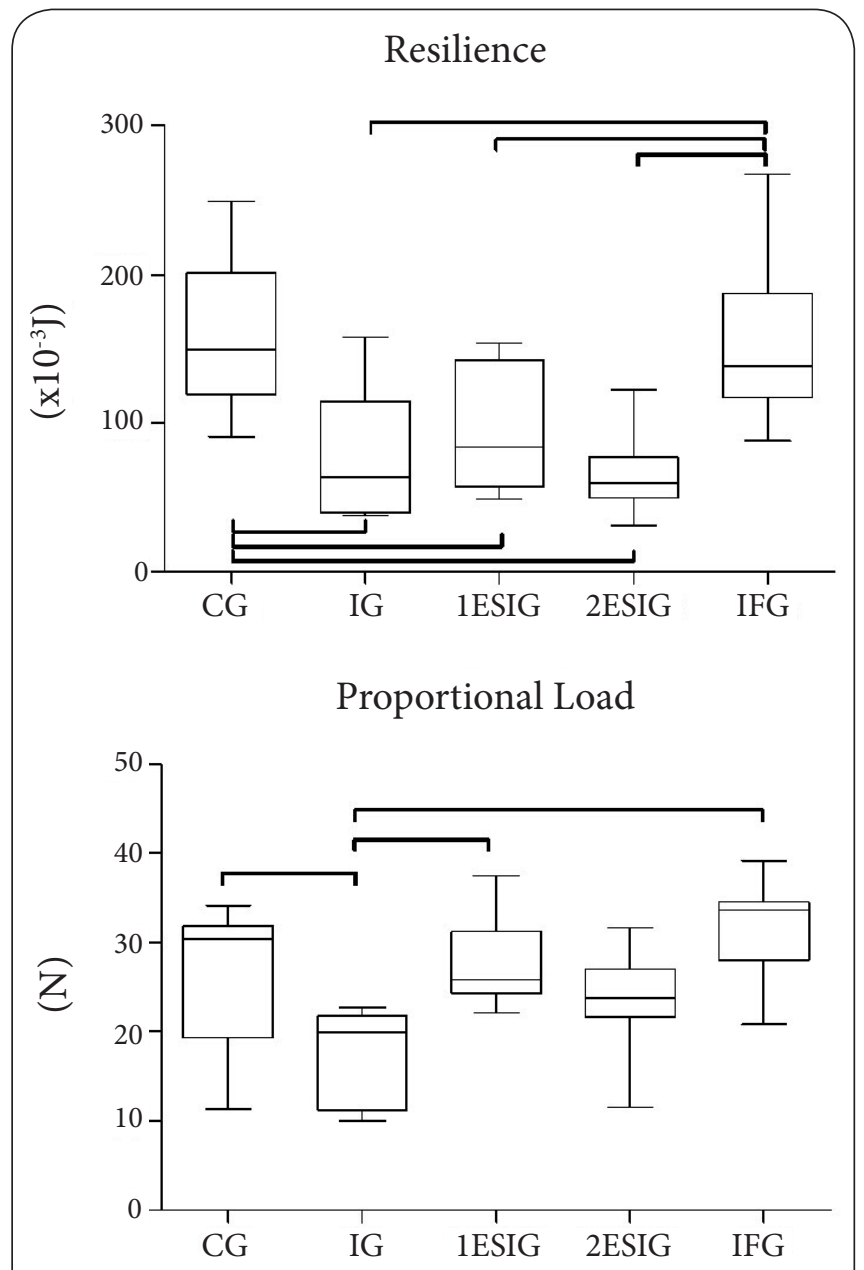

Proportional Elongation

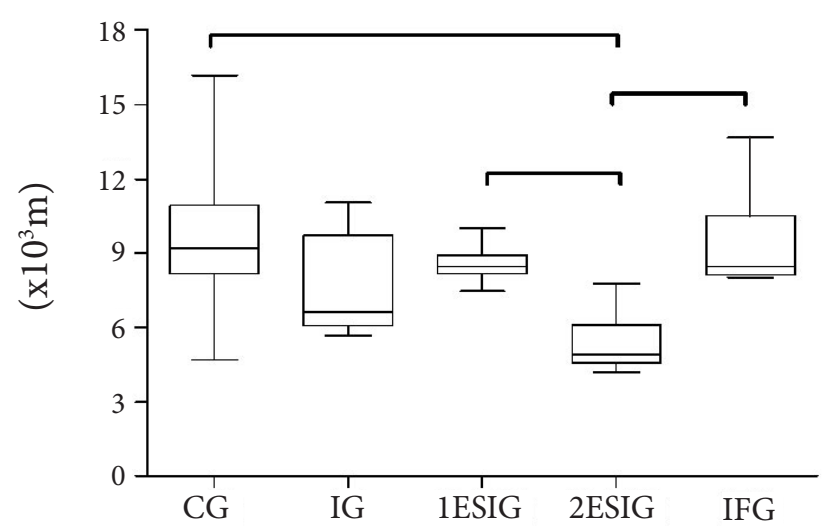

Figure 1. Mechanical properties evaluated in the studied groups: control (CG; n:10), immobilized (IG; n:10), immobilized and subjected to NMES once a day (1ESIG; n:10), immobilized and subjected to NMES twice a day (2ESIG; n:10), and immobilized then freed (IFG; n:10). Bars $P<0.05$.

\section{Fiber proportion}

The percentages of fiber types and subtypes observed in the medial portion of the gastrocnemius muscle of each experimental group (Table 2). The 1ESIG and the 2ESIG suffered significant reductions of TllaF.

The percentage of type llad fiber (TIladF) was also reduced in the $1 \mathrm{ESIG}$ compared to the $\mathrm{CG}$ and the IFG $(P<0.05)$. Type Ilc fiber (TIlcF) were significantly increased in the 1ESIG compared to the control and only immobilized groups (1ESIG vs CG; IG; $P<0.05)$. The remaining fibers, TIF, TIldF, TIldbF and TllbF, did not differ significantly among the groups.

No significant differences in the percentage of TIF, TllaF, TlladF, TIldF, TIldbF and TIIbF in the lateral portion of the gastrocnemius muscle were observed among the groups. Only TIIcF was significantly increased in the 1ESIG compared to the IG and the IFG (Table 3).

\section{Cross-sectional area}

The results of the statistical analysis of the mean cross-sectional area of the medial gastrocnemius muscle fibers are presented in Figure 2. Simultaneous analysis of the variance indicated a significant difference only for TIF), TIladF and TIIdFF (ANOVA; $P<0.001$ ). Immobilization reduced the size of the cross-sectional area of TIF, TIladF and TIIdF (IG vs CG; $P<0.001$ ). NMES applied once a day was able to reestablish the cross-sectional area of TIF and TIIdF (1ESIG vs CG; $P>0.05$ ) and produced values higher than those of the IG (1ESIG vs IG; $P<0.001)$. When NMES was applied twice a day, the section area was not reestablished for TIF, TIladF and TIIdF (2ESIG vs CG; $P<0.001$ ). The $1 \mathrm{ESIG}$ showed a considerable increase in the section area of TIlbF. These fibers were not detected in the control animals but were present in the IG. The same increase was observed in the 2ESIG. Free remobilization was able to reestablish the values of the section areas only for TIladF (IFG vs II; $P<0.001$ ), with a significant reduction being observed in TIIdF compared to the CG (IFG vs CG; $P<0.001$ ) (see Figure 2).

For the lateral portion of the gastrocnemius muscle, only TIF, TIladF and TIIdF were analyzed, but no difference was detected among groups $(P<0.05)$.

\section{Intramuscular connective tissues}

The mean quantities of intramuscular connective tissues of

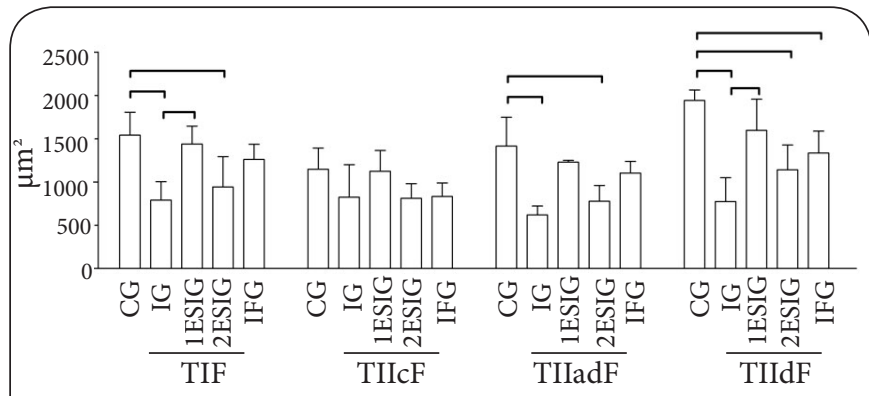

Figure 2. The cross-sectional areas $\left(\mu \mathrm{m}^{2}\right)$ of the medial gastrocnemius muscle fibers of the studied groups. FTI; FTIIad; FTIId. Bars $P<0.05$. 
Carvalho et al. Musculoskeletal Biology 2015,

http://www.hoajonline.com/journals/pdf/2054-720X-2-1.pdf

Table 1. Animals percentage with morphological alterations in the lateral (LG) and medial (MG) gastrocnemius muscles in the studied groups.

\begin{tabular}{l|cccccccccccc}
\hline \multirow{2}{*}{ Alterations (\%) } & \multicolumn{10}{c}{ Groups } \\
\cline { 2 - 13 } & \multicolumn{1}{c}{ CG $^{*}$} & \multicolumn{1}{c}{ IG $^{*}$} & 1ESIG $^{*}$ & \multicolumn{2}{c}{ 2ESIG* $^{*}$} & \multicolumn{2}{c}{ IFG $^{*}$} \\
\hline Nuclear centralization & 33 & 33 & 83 & 66 & 16 & 66 & 50 & 33 & 83 & 66 \\
Lobulated fibers & -- & 33 & 66 & 83 & 16 & 33 & 33 & -- & 33 & -- \\
Hyaline necrosis & -- & 66 & 33 & 83 & -- & -- & 33 & -- & 33 & 33 \\
Necrosis and cell degeneration & 16 & 66 & 83 & 100 & 66 & 100 & 100 & 100 & 83 & 100 \\
Regeneration & 16 & 16 & 33 & 50 & 16 & 66 & 33 & 50 & -- & 50 \\
Splitting & -- & -- & 66 & 33 & 50 & 50 & 33 & 33 & 83 & 33 \\
Central core & -- & 33 & -- & 66 & 16 & -- & 50 & 16 & 16 & 66 \\
Basophilic halo & 16 & 83 & -- & 66 & -- & 50 & 16 & 33 & 83 & 16 \\
\hline
\end{tabular}

${ }^{\star}$ Less than five percent of the cells were identified per evaluated field; -Not detected

Table 2. Media $\pm \mathrm{SD}$ of the percentages of fiber types observed in the medial portion of the gastrocnemius muscle in the groups: Control (CG); Immobilized (IG); Immobilized and subjected to NMES once a day (1ESIG), and Immobilized and subjected to NMES twice a day (2ESIG); Immobilized and then free (IFG).

\begin{tabular}{l|lllllll}
\hline \multirow{2}{*}{ Groups } & \multicolumn{7}{c}{ Type fibers } \\
\cline { 2 - 8 } & I & IIc & IIa & IIad $^{\mathbf{\Delta}}$ & IId $^{\mathbf{A}}$ & IIdb & IIb \\
\hline CG & $15.49 \pm 4.38$ & $1.38 \pm 3.04$ & $17.30 \pm 4.54$ & $12.69 \pm 5.59$ & $52.80 \pm 5.68$ & -- & $0.33 \pm 0.81$ \\
IG & $15.64 \pm 6.43$ & $1.09 \pm 0.95$ & $13.19 \pm 7.61$ & $6.70 \pm 3.29$ & $62.92 \pm 12.36$ & -- & $0.46 \pm 0.47$ \\
1ESIG & $15.28 \pm 9.87$ & $11.01 \pm 4.63^{*, \Delta}$ & - & $2.13 \pm 3.47^{*, *}$ & $68.85 \pm 11.41$ & $1.78 \pm 4.35$ & $0.96 \pm 1.31$ \\
2ESIG & $16.32 \pm 6.56$ & $7.99 \pm 4.36$ & -- & $7.99 \pm 6.55$ & $66.60 \pm 4.28$ & -- & $1.09 \pm 1.26$ \\
IFG & $22.51 \pm 5.92$ & $3.52 \pm 2.78$ & $7.18 \pm 4.63$ & $12.22 \pm 2.09$ & $54.21 \pm 7.17$ & $0.36 \pm 0.89$ & -- \\
\hline
\end{tabular}

${ }^{\Delta}$ Kruskal-Wallis Test $(P<0.05)$; Dunnet Test-*versus CG; ${ }^{\Delta}$ versus IG; * versus IFG $(P<0.05)$; Not detected

Table 3. Media $\pm S D$ of the percentages of fiber types observed in the lateral portion of the gastrocnemius muscle in the groups: Control (CG); Immobilized (IG); Immobilized and subjected to NMES once a day (1ESIG), and Immobilized and subjected to NMES twice a day (2ESIG); Immobilized and then free (IFG).

\begin{tabular}{l|lllllll}
\hline \multirow{2}{*}{ Groups } & \multicolumn{7}{c}{ Type fibers } \\
\cline { 2 - 8 } & I & IIc & IIa & IIad & IId & IIdb & IIb \\
\hline CG & $21.47 \pm 6.29$ & $1.29 \pm 0.63$ & $6.65 \pm 8.49$ & $15.55 \pm 8.96$ & $55.70 \pm 6.46$ & -- & -- \\
IG & $19.69 \pm 5.55$ & -- & $2.23 \pm 2.33$ & $12.40 \pm 9.05$ & $61.84 \pm 28.38$ & $1.23 \pm 2.08$ & -- \\
IESIG & $18.86 \pm 13.18$ & $15.34 \pm 9.03^{*, \#}$ & $6.77 \pm 14.25$ & $4.71 \pm 5.59$ & $54.32 \pm 19.78$ & -- & -- \\
2ESIG & $21.06 \pm 12.29$ & $4.74 \pm 5.95$ & -- & $7.57 \pm 8.34$ & $60.90 \pm 21.29$ & $1.15 \pm 1.56$ & $4.58 \pm 5.85$ \\
IFG & $31.76 \pm 14.09$ & $1.24 \pm 0.80$ & $3.01 \pm 4.67$ & $16.70 \pm 9.89$ & $47.72 \pm 31.53$ & -- & -- \\
\hline
\end{tabular}

${ }^{\Delta}$ Kruskal-Wallis test $(P<0.05)$; Dunnet test: *versus CG; " versus IFG $(P<0.05)$; ${ }^{-N o t}$ detected

each group are illustrated in Figure 3. For the medial portion of the muscle, only the $1 \mathrm{ESIG}$ and the $2 \mathrm{ESIG}$ presented mean connective tissue values significantly lower than those of the CG (CG vs 1ESIG; 2ESIG; $P<0.05$ ). In the lateral portion of the muscle, only the quantity of the connective tissues increased in the $2 \mathrm{ESIG}$ compared to the CG $(P<0.05)$.

\section{Discussion}

The immobilization reduced the values of the LLP and the Resilience mechanical properties as well as promoted increased numbers of fibers presenting necrosis/degeneration, with greater expression in the lateral portion of the muscle. The medial portion of the muscle showed atrophy of the TIF, 
Carvalho et al. Musculoskeletal Biology 2015,

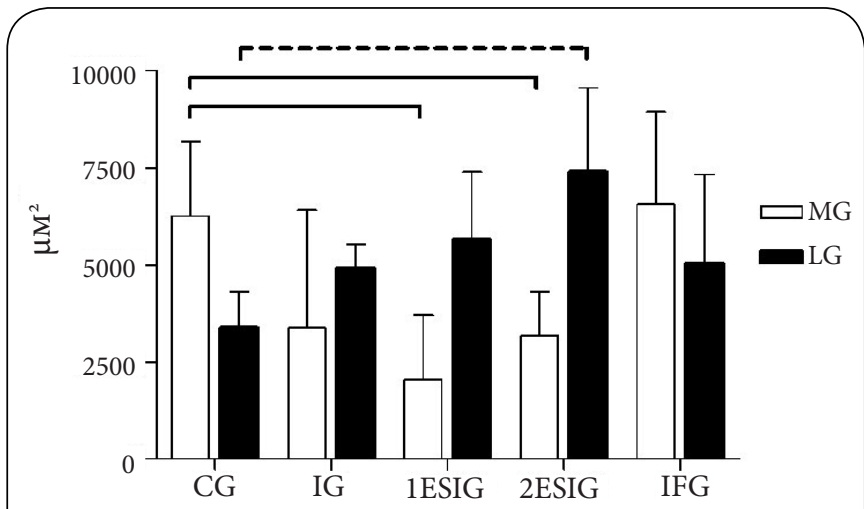

Figure 3. Quantity of the connective tissues in the studied groups: control (CG; n:6), immobilized (IG; n:6), immobilized and subjected to NMES once a day (1ESIG; n:6), immobilized and subjected to NMES twice a day (2ESIG: n:6), and immobilized then freed (IFG; n:6). MG: Medial Gastrocnemius. LG: Lateral Gastrocnemius. Bars $P<0.05$.

TlladF and TIldF, reduction of the TIlcF and Tllad numbers and no change in the amount of the intramuscular connective tissues. A previous study carried out in the laboratory showed that two weeks of immobilization in a shortened position atrophied TIF and TIIF [10], a fact that seems to be associated with an increase in proteolysis rather than with a decrease in protein synthesis [20]. This disequilibrium, in its turn, causes a reduction of the muscle volume, contraction force and amount of sarcomeres in series, especially when the muscle is maintained in shortened positions [21]. The detected changes in the mechanical properties must be associated with the reduced capacity of elongating in the elastic and plastic limits [12], as well as with the reduced stiffness and resilience. Clinically in humans, the knee immobilizing in extension promotes a reduction in the section of the quadriceps muscle area associated with increased in the relative mRNA expression of Myogenin, Myostatin, MyoD, MAFbx, P70S6K, LAT1/ SLC, PAT1 and associated occurs a strength muscle decrease in $9 \%$ after five days of immobilization [22].

When NMES was applied once a day after the period of immobilization, LLP property returned the control patterns, however this did not occur when the technique was applied twice a day. An interesting observation was the reduced capacity for energy absorption in the elastic phase of 2ESIG, which presented the lowest value compared to the $1 \mathrm{ESIG}$ and IFG. Parallel findings obtained in the present study may justify these results.

The intramuscular connective tissues are responsible for the changes of the passive tension in the muscle [23], so that their cells can identify the magnitude, the mode and the direction of the mechanical force applied [24]. The adopted immobilization procedure allowed that the muscle stays shortened, however it is believed that the lateral and medial portions of the muscle responded to the immobilization period in a different way. Such a result can be explained by the difference in muscle fascicle lengths among the different portions of the sural triceps. Kawakami et al., [25] reported that the articular angles and the internal as well as external fascicle designs in human beings can be different in the different portions of the gastrocnemius muscles. Moreover, it is believed that the lateral portion during (IG) and after (IFG) the immobilization period could have presented reduction in its contraction activity, knowing that while shortening the sural triceps a reduction in the muscle's lateral portion's activation occurs in human beings which would explain the increase in the conjunctive tissue [26]. However, analyzing the electrostimulated groups it is evident that the NMES procedure could have been concentrated in one of the muscle's portions, knowing that it was performed using only one electrode for both regions. In an experimental model of disuse for suspension, it was demonstrated that NMES applied twice a day (sine wave, 100 $\mathrm{Hz}, 500 \mathrm{~ms}$ ) promotes the reduction in the speed of atrophy of the soleus and gastrocnemius muscles in both deep and superficial layers [27]. In humans, NMES applied twice a day (biphasic symmetrical rectangular-wave pulses, $100 \mathrm{~Hz}, 400 \mu \mathrm{s}$ ) for five days of immobilization promotes increased fiber type II CSA, associated with maintenance of the relative mRNA expression and p70S6K and myostatin reduction of MAFbx, MyoD and Myogenin, but did not increase the capacity of generate strength [22].

The data obtained revealed an increase in the quantity of the connective tissue in the lateral gastrocnemius muscle and the reduction of the same tissue in the medial region of the muscle groups $1 \mathrm{ESIG}$ and 2ESIG may have been responsible for the resilience alterations. Both NMES protocols accentuated responses derived from the period of immobilization. It is believed that it could have occurred because of the increase in the expression of the mechanical growth factor (MGF) and the connective tissues growth factor (CTGF), thus activating signaling cascades that resulted in the increased expression of collagen I and III in the muscle [6], which contributes to changes in the resilience in these groups.

Another fact that explains the reduced resilience obtained in the 2ESIG is the atrophy of TIF, TIladF and TIldF observed in the gastrocnemius muscle's medial portion after the application of NMES twice a day. The quantitative data for the 1ESIG indicate a return of TIF and TIIdF to the control conditions, what would justify responses proportional load and elongation. Studies using NMES once a day during $[\mathbf{1 1 , 2 8}]$ and after periods of immobilization [10], or applying it to healthy animals have detected an increase in the cross-sectional area (CSA) of the muscle fibers with a predominance of TIF and TIIF in the gastrocnemius muscle $[10,11,28]$. Data regarding the proportions of muscle fibers seem to indicate that NMES applied once a day increased the percentage of TIlcF in both portions of the gastrocnemius muscle, on the other hand reduced the TllaF quantity. This was not observed in animals freely moving in their cages. 
Carvalho et al. Musculoskeletal Biology 2015,

Another fact that stood out was the reduction of the TllaF, since the presence of these fibers in the electrostimulated muscles was not detected. Associated with this, there was an increase in the number of TllcFs in the groups submitted to the NMES. Moreover, the TlldbF were present in the medial portion of the $1 \mathrm{ESIG}$ and lateral portion of the 2ESIG. These results suggest that the transitions were in the opposite directions from the $\mathrm{TIlaF} \leftrightarrow \mathrm{TIlbF} \leftrightarrow \mathrm{TIldbF} \leftrightarrow \mathrm{TIIdF} \leftrightarrow \mathrm{TIladF} \leftrightarrow \mathrm{TIlaF} \leftrightarrow$ TIIcF $\leftrightarrow$ TIF. However, when the NMES was applied for a longer period than used in this study, with a low frequency $(10 \mathrm{~Hz})$, the fibers to be first recruited were the TIIdFs, which underwent transition in one-way, being in the TIIdF $\leftrightarrow \mathrm{TIladF} \leftrightarrow \mathrm{TIlaF} \leftrightarrow \mathrm{TIF}$ direction [28]. Thus, it can be seen that, regardless of the applied time of NMES, the initial recruitment involved the TIIF fibers [30], even though a fiber transition occurs later. The findings in our study suggest that this transitional fiber event appears to be related to the expression of myostatin since an increase in Ilb fibers together with a reduction of TllaF and TIcF an be observed in the myostatin-null (-/-) rats [27], data not evaluated in the study. Another observation regarding the TlaF reduction would be the limitation of the fiber type (classifying) technique which could disguise its classification, nevertheless all methodological care as followed as described in other studies $[18,19]$.

Free remobilization allowed the reestablishment of all mechanical properties, and the morphology of this group demonstrated the presence animals with changes such as centralized nuclei, necrosis/degeneration, splitting and basophilic haloes in a few fibers. The results indicate that the IFG animals presented responses similar to those of the 1ESIG, suggesting that the release model adopted can contribute to muscle stretching after the period of immobilization. Using a similar protocol, Mattiello-Sverzut et al., [10] showed that the release induced only irregularities in fiber contour.

Clinically, once daily NMES (asymmetric biphasic pulsed, $8.9 \mathrm{~Hz}, 300 \mu \mathrm{s}$, 3hours/days, For six weeks) promotes gains in muscle strength in fractured patients [27]. Patients submitted to hip arthroplasty and treated with NMES (biphasic current, $40 \mathrm{~Hz}, 300 \mu \mathrm{s}$, 1 hour/day, For twelve days), also benefit because they increase walking-speed and reduce the time to Stair-climbing and sit-to-stand [29].

However, when the same resource is used only for five consecutive days during the period of immobilization and applied twice a day, is not capable of promoting significant increase in the capacity to generate muscular strength [22]. As reported, even with satisfactory clinical results, there are different patterns of NMES application, with controversial results. In this study the capacity to generate force during muscle contraction has not been evaluated, which is a limitation. However, there was post-immobilization NMES can produce effects on similarly elastic phase, regardless of the number of uses a single day.

Thus further studies are needed to identify how many times a day would be suitable for the best muscle response after periods of immobilization, as well as the ideal frequency ranges for each muscle composition to contribute to the functional recovery in a shorter time.

\section{Conclusion}

On the basis of the protocols applied in the present study, we conclude that the muscle remobilization intensity can, either positively or negatively, influence the recovery responses post-immobilization, for as it was observed, once daily neuromuscular electrical stimulation (NMES) can recover most mechanical parameters (except resilience) and structural parameters of gastrocnemius muscle after casting, whereas twice daily NMES promoted more significant deleterious effects to muscles. Associate, the free movement imposed to animals, allowed them to identify their own mobilization limits, which did not cause mechanical nor structural overload in the muscles evaluated.

\section{Competing interests}

The authors declare that they have no competing interests.

Authors' contributions

\begin{tabular}{|l|c|c|c|c|c|c|}
\hline Authors' contributions & LC & JP & FF & NP & AS & AM \\
\hline Research concept and design & $\checkmark$ & -- & -- & -- & $\checkmark$ & $\checkmark$ \\
\hline Collection and/or assembly of data & $\checkmark$ & $\checkmark$ & $\checkmark$ & $\checkmark$ & -- & -- \\
\hline Data analysis and interpretation & $\checkmark$ & $\checkmark$ & -- & -- & -- & $\checkmark$ \\
\hline Writing the article & $\checkmark$ & $\checkmark$ & -- & -- & -- & $\checkmark$ \\
\hline Critical revision of the article & $\checkmark$ & -- & -- & -- & -- & -- \\
\hline Final approval of article & $\checkmark$ & $\checkmark$ & $\checkmark$ & $\checkmark$ & $\checkmark$ & $\checkmark$ \\
\hline Statistical analysis & $\checkmark$ & -- & -- & -- & -- & -- \\
\hline
\end{tabular}

Acknowledgement

The authors wish to thank The Research and Care Foundation of the São Paulo University's Medicine College Hospital in Ribeirão Preto (FAEPA) and The National Council for Scientific and Technological Development (CNPq) for the financial support as well as the Bioengineering and Neuropathology Laboratories technicians from FMRP-USP for their valuable assistance.

Publication history

Editor: Hansjoerg Keller, Novartis Institutes for BioMedical Research, Switzerland.

Senior Editor: Shigeru Kotake, Tokyo Women's Medical University, Japan.

Received: 11-Feb-2015 Final Revised: 23-Mar-2015

Accepted: 26-Mar-2015 Published: 01-Apr-2015

\section{References}

1. Kannus $P$, Jozsa L, Jarvinen $T L$, Kvist $M$, Vieno $T$, Jarvinen $T A$, Natri $A$ and Jarvinen $M$. Free mobilization and low- to high-intensity exercise in immobilization-induced muscle atrophy. J Appl Physiol (1985). 1998; 84:1418-24. | Article | PubMed

2. Boonyarom $\mathrm{O}$ and Inui K. Atrophy and hypertrophy of skeletal muscles: structural and functional aspects. Acta Physiol (Oxf). 2006; 188:77-89. | Article | PubMed

3. Hamill OP and Martinac B. Molecular basis of mechanotransduction in living cells. Physiol Rev. 2001; 81:685-740. | Article | PubMed

4. Kjaer M. Role of extracellular matrix in adaptation of tendon and 
Carvalho et al. Musculoskeletal Biology 2015,

http://www.hoajonline.com/journals/pdf/2054-720X-2-1.pdf

doi: 10.7243/2054-720X-2-1

skeletal muscle to mechanical loading. Physiol Rev. 2004; 84:649-98. | Article | PubMed

5. Capetanaki Y, Bloch RJ, Kouloumenta A, Mavroidis M and Psarras S. Muscle intermediate filaments and their links to membranes and membranous organelles. Exp Cell Res. 2007; 313:2063-76. | Article | PubMed

6. Heinemeier KM, Olesen JL, Haddad F, Langberg H, Kjaer M, Baldwin KM and Schjerling P. Expression of collagen and related growth factors in rat tendon and skeletal muscle in response to specific contraction types. $J$ Physiol. 2007; 582:1303-16. | Article I PubMed Abstract I PubMed Full $\underline{\text { Text }}$

7. Burkholder TJ. Mechanotransduction in skeletal muscle. Front Biosci. 2007; 12:174-91. | Article | PubMed Abstract | PubMed Full Text

8. Carvalho LC, Shimano AC and Picado $\mathrm{CH}$. Neuromuscular electric stimulation and manual passive stretching when recovering mechanical properties of immobilized gastrocnemius muscles. Acta Ortop. Bras 2008; 16:161-164. | Article

9. Williams PE and Goldspink G. Connective tissue changes in immobilized muscle. J. Anat. 1984; 138:343-350. I Article

10. Mattiello-Sverzut AC, Carvalho LC, Cornachione A, Nagashima M, Neder $L$ and Shimano AC. Morphological effects of electrical stimulation and intermittent muscle stretch after immobilization in soleus muscle. Histol Histopathol. 2006; 21:957-64. | Article | PubMed

11. Qin L, Appell HJ, Chan KM and Maffulli N. Electrical stimulation prevents immobilization atrophy in skeletal muscle of rabbits. Arch Phys Med Rehabil. 1997; 78:512-7. | Article | PubMed

12. Carvalho LC, Polizello JC, Padula N, Freitas FC, Shimano AC and MattielloSverzut AC. Mechanical properties of gastrocnemius eletrostimulated after immobilization. Acta Ortop. Bras. 2009; 17:269-272. | Article

13. Bax L, Staes F and Verhagen A. Does neuromuscular electrical stimulation strengthen the quadriceps femoris? A systematic review of randomised controlled trials. Sports Med. 2005; 35:191-212. | Article | PubMed

14. Kim KM, Croy T, Hertel J and Saliba S. Effects of neuromuscular electrical stimulation after anterior cruciate ligament reconstruction on quadriceps strength, function, and patient-oriented outcomes: a systematic review. J Orthop Sports Phys Ther. 2010; 40:383-91. | Article I PubMed

15. Mintken PE, Carpenter KJ, Eckhoff D, Kohrt WM and Stevens JE. Early neuromuscular electrical stimulation to optimize quadriceps muscle function following total knee arthroplasty: a case report. J Orthop Sports Phys Ther. 2007; 37:364-71. | Article | PubMed

16. Stevens-Lapsley JE, Balter JE, Wolfe P, Eckhoff DG and Kohrt WM. Early neuromuscular electrical stimulation to improve quadriceps muscle strength after total knee arthroplasty: a randomized controlled trial. Phys Ther. 2012; 92:210-26. | Article | PubMed Abstract | PubMed Full Text

17. Thomas AC and Stevens-Lapsley JE. Importance of attenuating quadriceps activation deficits after total knee arthroplasty. Exerc Sport Sci Rev. 2012; 40:95-101. | Article | PubMed Abstract | PubMed Full Text

18. Staron RS, Kraemer WJ, Hikida RS, Fry AC, Murray JD and Campos GE. Fiber type composition of four hindlimb muscles of adult Fisher 344 rats. Histochem Cell Biol. 1999; 111:117-23. | Article | PubMed

19. Cornachione AS, Benedini-Elias PC, Polizello JC, Carvalho LC and Mattiello-Sverzut AC. Characterization of fiber types in different muscles of the hindlimb in female weanling and adult Wistar rats. Acta Histochem Cytochem. 2011; 44:43-50. | Article | PubMed Abstract | PubMed Full Text

20. Jackman RW and Kandarian SC. The molecular basis of skeletal muscle atrophy. Am J Physiol Cell Physiol. 2004; 287:C834-43. I Article I PubMed

21. Frimel TN, Kapadia F, Gaidosh GS, Li Y, Walter GA and Vandenborne K. A model of muscle atrophy using cast immobilization in mice. Muscle Nerve. 2005; 32:672-4. I Article I PubMed
22. Dirks ML, Wall BT, Snijders T, Ottenbros CL, Verdijk LB and van Loon LJ. Neuromuscular electrical stimulation prevents muscle disuse atrophy during leg immobilization in humans. Acta Physiol (Oxf). 2014; 210:62841. | Article | PubMed

23. Jarvinen TA, Jozsa L, Kannus $P$, Jarvinen TL and Jarvinen M. Organization and distribution of intramuscular connective tissue in normal and immobilized skeletal muscles. An immunohistochemical, polarization and scanning electron microscopic study. J Muscle Res Cell Motil. 2002; 23:245-54. | Article | PubMed

24. Chiquet M, Gelman L, Lutz R and Maier S. From mechanotransduction to extracellular matrix gene expression in fibroblasts. Biochim Biophys Acta. 2009; 1793:911-20. | Article | PubMed

25. Kawakami Y, Ichinose $Y$ and Fukunaga T. Architectural and functional features of human triceps surae muscles during contraction. J Appl Physiol (1985). 1998; 85:398-404. | Article | PubMed

26. Sasaki K and Ishii N. Shortening velocity of human triceps surae muscle measured with the slack test in vivo. J Physiol. 2005; 567:1047-56. | Article | PubMed Abstract | PubMed Full Text

27. Tanaka $\mathrm{M}$, Hirayama $\mathrm{Y}$, Fujita $\mathrm{N}$ and Fujino $\mathrm{H}$. Electrical stimulation using sine waveform prevents unloading-induced muscle atrophy in the deep calf muscles of rat. Acta Histochem. 2014; 116:1192-8. | Article | PubMed

28. Durigan JLQ, Cancelliero KM, Dias CKN, Silva CA, Guirro RRJ and Polacow MLO. Effects of neuromuscular electrical stimulation on rat hind limbs immobilized for 15 days: metabolic and morphometric analyses. Rev. Bras. Fisiot. 2006; 10:297-302. | Article

29. Suetta C, Magnusson SP, Rosted A, Aagaard P, Jakobsen AK, Larsen LH, Duus $B$ and Kjaer $M$. Resistance training in the early postoperative phase reduces hospitalization and leads to muscle hypertrophy in elderly hip surgery patients--a controlled, randomized study. J Am Geriatr Soc. 2004; 52:2016-22. I Article | PubMed

30. Pette $D$ and Staron RS. Transitions of muscle fiber phenotypic profiles. Histochem Cell Biol. 2001; 115:359-72. I Article I PubMed

31. Sinacore DR, Delitto A, King DS and Rose SJ. Type II fiber activation with electrical stimulation: a preliminary report. Phys Ther. 1990; 70:416-22. | Article | PubMed

32. Lamb SE, Oldham JA, Morse RE and Evans JG. Neuromuscular stimulation of the quadriceps muscle after hip fracture: a randomized controlled trial. Arch Phys Med Rehabil. 2002; 83:1087-92. I Article I PubMed

33. Suetta C, Magnusson SP, Rosted A, Aagaard P, Jakobsen AK, Larsen LH, Duus $B$ and Kjaer $M$. Resistance training in the early postoperative phase reduces hospitalization and leads to muscle hypertrophy in elderly hip surgery patients--a controlled, randomized study. J Am Geriatr Soc. 2004; 52:2016-22. | Article | PubMed

\section{Citation:}

Carvalho L, Polizello J, Freitas F, Padula N, Shimano A and Mattiello-Sverzut AC. Twice a day neuromuscular electrical stimulation postimmobilization alters the mechanical properties and the histomorphometry of the skeletal muscle. Musculoskelet Biol. 2015; 2:1. http://dx.doi.org/10.7243/2054-720X-2-1 